\title{
Editorial
}

\section{Evolution on Keratoconus and Corneal Ectatic Diseases: Paradigms and Paradoxes}

The first accurate description of keratoconus is reported to be the treatise on conical cornea published by Dr John Nottingham in London, in 1854. Interestingly, despite the limitations on the knowledge related to anatomy, biochemistry, and physiology of the eye, Nottingham's seminal work described in detail many aspects of the epidemiology, clinical presentation, and treatment of corneal ectatic diseases are still accurate today. ${ }^{1}$ Important contributions were made by different authors, but with much less consistency and accuracy. In fact, as reviewed by Grzybowski and McGhee, ectatic corneal diseases (ECDs) were bewilderingly denoted by several different terms including hyperkeratosis, conical formed cornea, cornea conica, sugar loaf cornea, prolapses corneae, procidentia corneae, staphyloma pellucidum, staphyloma diaphanum, keratoconus among other terms. ${ }^{2}$

The introduction of refractive surgery in the early 1990s led to a sudden need for increasing knowledge related to keratoconus and ECDs. This has led to a continuous revolution on the understanding and management of such diseases. ${ }^{3-5}$ Along with significant paradigm shifts, novel paradoxes have been identified for the clinician when managing such diseases. In fact, we have proposed that ectasia may be referred as a novel subspecialty in ophthalmology, considering the relatively high number of patients and the specific technologies related to diagnosis and treatment. ${ }^{3}$

A review of the PubMed literature on keratoconus finds 5,591 publications (PubMed search for "keratoconus" on 11th December, 2016). Prior to 1980, when modern refractive surgery was introduced, only 621 publications were found. Since then, an exponential increase is observed, so that over $40 \%$ of the articles were published in the last 5 years (Graph 1).

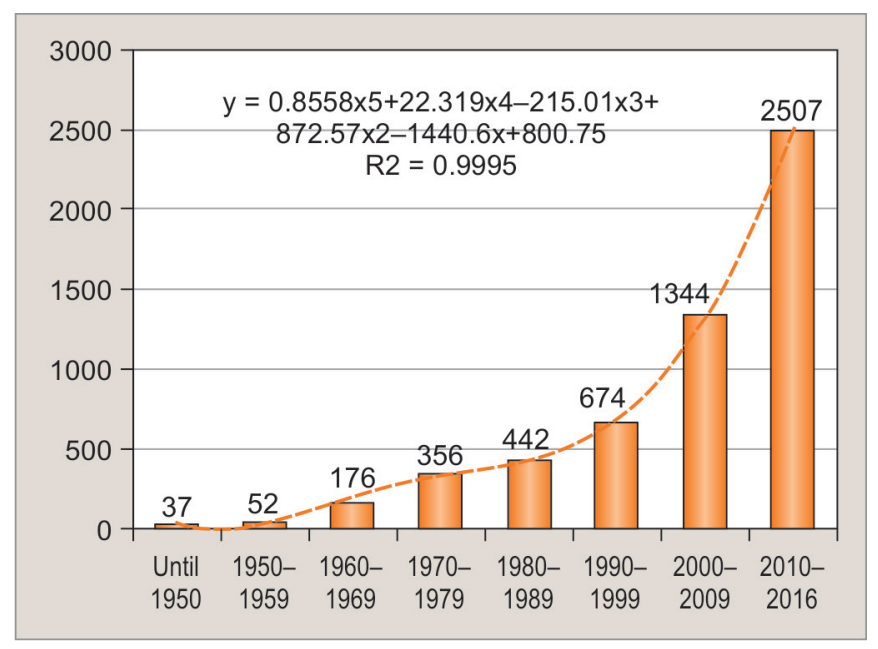

Graph 1: Number of publications on keratoconus on PubMed

Refractive surgery necessitated the need for earlier diagnosis of mild or subclinical forms of ECDs, as such cases are known to be at higher risk for progressive ectasia (keratectasia) after corneal procedures. ${ }^{6,7}$ More recently, newer therapeutic options, such as corneal crosslinking $(\mathrm{CXL}),={ }^{8}$ have also increased the requirement for both earlier and more accurate diagnosis of ectatic disease. ${ }^{4,5,9}$ The paradigm shift described by Seiler ${ }^{10}$ was based on the fact that less than 2 decades ago the management of ECD was more simplistic, typically limited to rigid contacts or penetrating keratoplasty. ${ }^{10}$ Novel treatments such as intrastromal rings were introduced to regularize the cornea, ${ }^{10}$ along with other treatments such as topography-guided photorefractive keratectomy and phakic intraocular lens implantation, ${ }^{11}$ which may be combined to CXL. ${ }^{12-14}$ In addition, the improvement on techniques for deep anterior lamellar keratoplasty has also significantly changed the management of ECD. ${ }^{15-17}$ While in the past, the major goal of treatment was visual rehabilitation after visual loss has occurred, newer and evolving treatments should attempt to prevent visual loss before they occur.

Clinicians are now faced with an increasing array of therapeutic options and treatment decisions need to be based on an accurate assessment of both patent needs, medical and anatomical findings, and environmental concerns. ${ }^{4,5,9}$ 
One of the most important decisions is the consideration of therapeutic $v s$ refractive elective treatments. ${ }^{18}$ In this context, patient and family education are essential for enabling conscious decisions. Additionally, the most important nonsurgical treatment measure is guidance not to rub the eyes, ${ }^{4,9}$ along with treatment of ocular allergy and optimization of ocular surface. ${ }^{19}$ Visual restoration should be first attempted with spectacles or contact lenses. Often requiring specially designed corneal or scleral lenses, contact lens fitting constitute the most effective treatment option. ${ }^{20}$ However, contact lenses provide visual restoration but do not prevent or slow disease progression. ${ }^{4,21}$ To prevent visual loss, CXL should be considered early in the disease process and ideally prior to changes on anterior corneal surface, which are associated with a reduction in spectacle acuity. At times, however, CXL can be associated with corneal haze and a mild reduction in best corrected vision. ${ }^{22}$ It is imperative, therefore, that a decision to proceed with CXL is made on solid grounds, based both on a firm diagnosis of keratoconus and documentation of ectasia progression. Thereby, documentation of ectasia progression has been considered as fundamental for determining the indication of $\mathrm{CXL}$, which has been reviewed by Duncan et al. ${ }^{23}$ Paradoxically, if not indicated, we should not proceed with any surgery, but when indicated, one should not wait too long. Thereby, the difficulty lies in avoiding unnecessary intervention, while not delaying treatment in progressive cases or cases likely to progress.

\section{Ectasia Susceptibility and Controversial aspects of Ectasia Diagnosis}

Ectasia progression after laser vision correction (LVC) occurs due to biomechanical decompensation of the cornea, which is related to the innate or inherent predisposition of the cornea and to the induced weakening caused by tissue removal. The impact from surgery is related to the number of lamellae that are severed during the procedure, being related to the residual stromal bed and to the percent of tissue altered. ${ }^{24-27}$

In practice, screening for ectasia susceptibility involves not only identifying early or subclinical disease but also involves the concept that even a "normal" eye can undergo ectatic degeneration if stressed beyond certain biomechanical limits. This is somehow related to the continuum of glaucoma, which has a subsymptomatic phase which may be detected by advanced propedeutics. ${ }^{28}$

Evolution in corneal imaging involves the development of high resolution technologies and methods for representing and interpreting the generated data for improving clinical decision. ${ }^{29}$ Front surface corneal topography derived from placido-disk reflection images evolved into three-dimensional tomographic analysis, which measures both anterior and posterior corneal surfaces and full pachymetric characteristics. ${ }^{30}$ Additional advances on corneal imaging include segmental or layered tomography with optical coherence tomography or very high frequency ultrasound for epithelial, ${ }^{31,32}$ and Bowman's layer thickness mapping. ${ }^{33}$ Clinical biomechanical assessment has the potential for identifying milder forms of ECD, along with characterization of the inherent susceptibility for ectasia progression. ${ }^{34,35}$ The Reichert Ocular Response Analyzer (Buffalo, NY, USA), ${ }^{36}$ and the Corvis ST (OCULUS Optikgeräte $\mathrm{GmbH}$, Wetzlar, Germany) are noncontact tonometers (NCTs) that monitor corneal deformation during the NCT measurement. ${ }^{37}$ Interestingly, the integration of corneal tomography and biomechanical assessments have been proposed to detect mild ectasia as well as to characterize ectasia susceptibility. ${ }^{35,38}$

Eyes with normal front curvature (topometric) findings from patients with clinical ectasia detected in the fellow eye have been used to demonstrate the improved ability of advanced corneal imaging devices to detect mild ECD. ${ }^{39-41}$ Klyce $^{42}$ referred to these cases to have forme fruste keratoconus, ${ }^{42}$ a term coined by Amsler ${ }^{43}$ in the early 1960 s based on photokeratoscopy. However, while most of these cases are expected to have subclinical disease where the anterior surface remains uninvolved, some of these cases may be true unilateral ectasia cases. ${ }^{44}$ In fact, there is a consensus that true unilateral keratoconus does not exist, this is also a consensus that secondary or induced ectasia may occur unilaterally. ${ }^{4}$ These ideas are in agreement with the two-hit hypothesis, which considers an underlying genetic predisposition combined with external environmental factors, such as, eye rubbing and atopy. ${ }^{5}$ For example, we reported two identical twins in which one of them, who admitted to have rubbed the eye during early adulthood, had very asymmetric ectasia with normal anterior curvature or topography in one eye and the other twin had normal topography in both eyes. ${ }^{45}$ A close to ideal study for assessing ectasia susceptibility may involve the analysis of the preoperative state of cases that developed keratectasia after laser in situ keratomileusis or other forms of ECD. ${ }^{34-36}$ This should also consider the surgical parameters which represent the impact from surgery on the cornea. ${ }^{46}$ Another limitation widely seen in studies involving diagnosis of keratoconus is the control population. Cases with stable corneas and long-term follow-up after LVC would provide a more robust population for the normal control group. ${ }^{39,46,47}$ 
Keratoconus and ECDs comprehend a very hot area for research and clinical interest. Considering the number of publications per year and per decade, we expect over 500 publications in the next year and that the number of published articles to duplicate within the next 10 years. We predict further advances on corneal imaging with further integration of technologies, along with an expansion on diagnosis into genetics and molecular biology. Also, novel less invasive modalities for CXL are expected to further improve our ability to help patients with such diseases.

\section{REFERENCES}

1. Gokul A, Patel DV, McGhee CN. Dr John Nottingham's 1854 Landmark Treatise on Conical Cornea Considered in the Context of the Current Knowledge of Keratoconus. Cornea 2016 May;35(5):673-678.

2. Grzybowski A, McGhee CN. The early history of keratoconus prior to Nottingham's landmark 1854 treatise on conical cornea: a review. Clin Exp Optom 2013 Mar;96(2):140-145.

3. Ambrósio RJ. Keratoconus and ectatic corneal diseases: Are we facing a new subspeciality? Int J Kerat Ect cor Dis 2012;1:vii.

4. Gomes JA, Tan D, Rapuano CJ, Belin MW, Ambrósio R Jr, Guell JL, Malecaze F, Nishida K, Sangwan VS; Group of Panelists for the Global Delphi Panel of Keratoconus and Ectatic Diseases. Global consensus on keratoconus and ectatic diseases. Cornea 2015 Apr;34(4):359-369.

5. McGhee CN, Kim BZ, Wilson PJ. Contemporary treatment paradigms in keratoconus. Cornea 2015 Oct;34 Suppl 10:S16-S23.

6. Binder PS, Lindstrom RL, Stulting RD, Donnenfeld E, Wu H, McDonnell P, Rabinowitz Y. Keratoconus and corneal ectasia after LASIK. J Refract Surg 2005 Nov-Dec;21(6):749-752.

7. Ambrosio R Jr, Randleman JB. Screening for ectasia risk: what are we screening for and how should we screen for it? J Refract Surg 2013 Apr;29(4):230-232.

8. Wollensak G, Spoerl E, Seiler T. Riboflavin/ultraviolet-a-induced collagen crosslinking for the treatment of keratoconus. Am J Ophthalmol 2003 May;135(5):620-627.

9. Faria-Correia F LA, Ambrosio R Jr. Managing corneal ectasia prior to keratoplasty. Expert Rev Ophthalmol 2015;10(1):49-58.

10. Seiler T. The paradigm change in keratoconus therapy. Indian J Ophthalmol 2013;61:381.

11. Ramirez-Miranda A, Jaimes M, Graue-Hernandez EO, Ramirez-Luquin T, Navas A. Toric intraocular lens in keratoconus. Cornea 2012 Mar;31(3):335-336.

12. Krueger RR, Kanellopoulos AJ. Stability of simultaneous topography-guided photorefractive keratectomy and riboflavin/UVA cross-linking for progressive keratoconus: case reports. J Refract Surg 2010 Oct;26(10):S827-S832.

13. Kanellopoulos AJ. Comparison of sequential vs same-day simultaneous collagen cross-linking and topography-guided PRK for treatment of keratoconus. J Refract Surg 2009 Sep;25(9):S812-S818.

14. Koller T, Iseli HP, Donitzky C, Ing D, Papadopoulos N, Seiler T. Topography-guided surface ablation for forme fruste keratoconus. Ophthalmology 2006 Dec;113(12):2198-2202.

15. Al-Torbak AA, Al-Motowa S, Al-Assiri A, Al-Kharashi S, Al-Shahwan S, Al-Mezaine H, Teichmann K. Deep anterior lamellar keratoplasty for keratoconus. Cornea 2006 May;25(4):408-412.

16. Fontana L, Parente G, Tassinari G. Clinical outcomes after deep anterior lamellar keratoplasty using the big-bubble technique in patients with keratoconus. Am J Ophthalmol 2007 Jan;143(1):117-124.

17. Parmar P, Salman A, Kalavathy CM, Thomas PA, Jesudasan NC. Simplified technique for deep anterior lamellar keratoplasty. Cornea 2007;26:707-708.

18. Ambrósio R Jr. Cirurgia refrativa terapêutica: por que diferenciar? Revista Brasileira de Oftalmologia 2013;72:85-86.

19. Sharma N, Rao K, Maharana PK, Vajpayee RB. Ocular allergy and keratoconus. Indian J Ophthalmol 2013 Aug;61(8):407-409.

20. Alio JL, Vega-Estrada A, Peña García P, Durán García ML, Sanz-Díez P. Keratoconus Management Guidelines. Int J Kerat Cor Ect Dis 2015;4 (in press)

21. Siqueira JA DL, Siqueira R, Valbon B, Santos R, Dawson D, Ambrosio R Jr. Long-term improvement after the athens protocol for advanced keratoconus with significant ectasia progression in the fellow eye. Int J Kerat Ect Cor Dis 2013;2:143-146.

22. Koller T, Mrochen M, Seiler T. Complication and failure rates after corneal crosslinking. J Cataract Refract Surg 2009 Aug;35(8):1358-1362.

23. Duncan JK, Belin MW, Borgstrom M. Assessing progression of keratoconus: novel tomographic determinants. Eye Vis (Lond) 2016 Mar 11;3:6.

24. Santhiago MR, Smadja D, Wilson SE, Krueger RR, Monteiro ML, Randleman JB. Role of percent tissue altered on ectasia after LASIK in eyes with suspicious topography. J Refract Surg 2015 Apr;31(4):258-265.

25. Santhiago MR, Smadja D, Gomes BF, Mello GR, Monteiro ML, Wilson SE, Randleman JB. Association between the percent tissue altered and post-laser in situ keratomileusis ectasia in eyes with normal preoperative topography. Am J Ophthalmol 2014 Jul;158(1):87-95.e1.

26. Ambrosio R Jr, Dawson DG, Belin MW. Association between the percent tissue altered and post-laser in situ keratomileusis ectasia in eyes with normal preoperative topography. Am J Ophthalmol 2014 Dec;158(6):1358-1359.

27. Ambrosio R Jr, Wilson SE. Complications of laser in situ keratomileusis: etiology, prevention, and treatment. J Refract Surg 2001;17:350-379.

28. Abe RY, Diniz-Filho A, Zangwill LM, Gracitelli CPB, Marvasti AH, Weinreb RN, Baig S, Medeiros FA. The relative odds of progressing by structural and functional tests in glaucoma. Invest Ophthalmol Vis Sci 2016;57:OCT421OCT428.

29. Salomao MQ, Esposito A, Dupps WJ Jr. Advances in anterior segment imaging and analysis. Curr Opin Ophthalmol 2009;20(4): 324-332. 
30. Ambrosio R Jr, Belin MW. Imaging of the cornea: topography vs tomography. J Refract Surg 2010 Nov;26(11):847-849.

31. Guan T, Liu C, Ma Z, Ding S. The point mutation and polymorphism in keratoconus candidate gene TGFBI in Chinese population. Gene 2012 Jul 15;503(1):137-139.

32. Reinstein DZ, Gobbe M, Archer TJ, Silverman RH, Coleman DJ. Epithelial, stromal, and total corneal thickness in keratoconus: three-dimensional display with artemis very-high frequency digital ultrasound. J Refract Surg 2010 Apr;26(4):259-271.

33. Pahuja N, Shroff R, Pahanpate P, Francis M, Veeboy L, Shetty R, Nuijts RM, Roy AS. Application of high resolution OCT to evaluate irregularity of Bowman's layer in asymmetric keratoconus. J Biophotonics 2016 Aug 24 [Epub ahead of print].

34. Ambrósio R Jr, Nogueira LP, Caldas DL, Fontes BM, Luz A, Cazal JO, Alves MR, Belin MW. Evaluation of corneal shape and biomechanics before LASIK. Int Ophthalmol Clin 2011 Spring;51(2):11-38.

35. Ambrosio R Jr, Dawson DG, Salomão M, Guerra FP, Caiado AL, Belin MW. Corneal ectasia after LASIK despite low preoperative risk: tomographic and biomechanical findings in the unoperated, stable, fellow eye. J Refract Surg 2010 Nov;26(11):906-911.

36. Luce DA. Determining in vivo biomechanical properties of the cornea with an ocular response analyzer. J Cataract Refract Surg 2005 Jan;31(1):156-162.

37. Ambrósio R Jr, Ramos I, Luz A, Faria FC, Steinmueller A, Krug M, Belin MW, Roberts CJ. Dynamic ultra high speed scheimpflug imaging for assessing corneal biomechanical properties. Revista Brasileira de Oftalmologia 2013;72(2):99-102.

38. Luz A, Lopes B, Hallahan KM, Valbon B, Ramos I, Faria-Correia F, Schor P, Dupps WJ Jr, Ambrósio R Jr. Enhanced combined tomography and biomechanics data for distinguishing forme fruste keratoconus. J Refract Surg 2016 Jul 1;32(7):479-494.

39. Saad A, Gatinel D. Topographic and tomographic properties of forme fruste keratoconus corneas. Invest Ophthalmol Vis Sci 2010 Nov;51(11):5546-5555.

40. Ambrosio R Jr, Valbon BF, Faria-Correia F, Ramos I, Luz A. Scheimpflug imaging for laser refractive surgery. Curr Opin Ophthalmol 2013;24(4):310-320.

41. Smadja D, Touboul D, Cohen A, Doveh E, Santhiago MR, Mello GR, Krueger RR, Colin J. Detection of subclinical keratoconus using an automated decision tree classification. Am J Ophthalmol 2013 Aug;156(2):237-246.e1.

42. Klyce SD. Chasing the suspect: keratoconus. Br J Ophthalmol 2009 Jul;93(7):845-847.

43. Amsler M. [The "forme fruste" of keratoconus]. Wien Klin Wochenschr 1961 Dec 8;73:842-843.

44. Ramos IC, Reinstein DZ, Archer TJ, Gobbe M, Salomao MQ, Lopes B, Luz A, Faria-Correia F, Gatinel D, Belin MW, Ambrósio R Jr. Unilateral ectasia characterized by advanced diagnostic tests. Int J Kerat Ect Cor Dis 2016;5:40-51.

45. Guerra G, de Oliveira VB, Ferreira I, Ramos I, Belin MW, Ambrósio R Jr. Subclinical keratoconus detection in identical twins. Int J Kerat Ect Cor Dis 2016;5(1):35-39.

46. Ambrósio R Jr, Ramos I, Lopes B, et al. Assessing ectasia susceptibility prior to LASIK: the role of age and residual stromal bed (RSB) in conjunction to Belin-Ambrósio deviation index (BAD-D). Revista Brasileira de Oftalmologia 2014;73:75-80.

47. Ambrósio R Jr, Lopes B, Faria-Correia F, Vinciguerra R, Vinciguerra P, Elsheikh A, Roberts CJ. Ectasia detection by the assessment of corneal biomechanics. Cornea 2016 Jul;35(7):e18-e20.

Renato Ambrosio Jr MD, PhD

Rio de Janeiro Corneal Tomography and Biomechanics Study Group, Rio de Janeiro, Brazil Department of Ophthalmology, Federal University of São Paulo, São Paulo, Brazil Department of Ophthalmology, Pontific Catholic University of Rio de Janeiro, Rio de Janeiro, Brazil

Fernando Faria-Correia MD

Rio de Janeiro Corneal Tomography and Biomechanics Study Group, Rio de Janeiro, Brazil School of Health Sciences, University of Minho, Braga, Portugal

Bernardo Lopes MD

Rio de Janeiro Corneal Tomography and Biomechanics Study Group, Rio de Janeiro, Brazil Department of Ophthalmology, Federal University of São Paulo, São Paulo, Brazil

Marcella Salomão MD

Rio de Janeiro Corneal Tomography and Biomechanics Study Group, Rio de Janeiro, Brazil Department of Ophthalmology, Federal University of São Paulo, São Paulo, Brazil

Michael W Belin MD

Department of Ophthalmology and Vision Science, University of Arizona, Tucson, Arizona, USA 